\title{
Emergencia de viejos temas en un contexto modernizado: marco teórico metodológico en un estudio de migrantes estacionales al sur de Argentina'
}

\author{
Appearance of Old Topics in a Modernized Context: \\ Theoretical and Methodological Framework \\ in the Study of Seasonal Migrants in Southern Argentina
}

\author{
Mónica Bendini, Norma Steimbreger y Martha Radonich ${ }^{2}$ \\ Universidad Nacional del Comahue - Argentina \\ grupo.gesa@fade.uncoma.edu.ar
}

Recibido: 16.06.2011

Aprobado definitivamente: 13.12.2011

\section{RESUMEN}

Este artículo se ocupa de realizar los recorridos teóricos y procedimentales en la construcción social de los datos y su reflexión analítica. Se muestra, desde la trastienda de la investigación, el devenir de un tema tradicional en un contexto modernizado. En esta ocasión, la investigación empírica se sitúa en una región de producción intensiva bajo riego en el Sur de Argentina orientada al mercado mundial, con elevados requerimientos de migrantes estacionales y con opacidad en los registros y en las imágenes sociales. Desde una ciencia social crítica y mediante la ruptura de lo obvio hemos procedido a construir datos y hallazgos para desnaturalizar representaciones y desmenuzar las situaciones a través de la combinación de procedimientos metodológicos. El propósito de este trabajo consiste, pues, en mostrar las decisiones teórico-metodológicas que subyacen en este camino y dar respuestas con contenido sustantivo y empírico a las preguntas de indagación central acerca de la migración estacional en una cadena frutícola.

Palabras Clave: enclaves de agricultura intensiva, trabajadores estacionales, migraciones, globalización de la agricultura.

\footnotetext{
ABSTRACT

This article deals with carrying out the theoretical and procedural developments in the social construction of data and analytical thinking. From the back room of research, it is shown the progress of a traditional topic in a modernized context. This time, empirical research is situated in a region of intensive production under

${ }^{1}$ Este trabajo reúne algunos materiales del proyecto Grupo de Estudios Sociales Agrarios (GESA), Facultad de Derecho y Ciencias Sociales - FONCYT, PICT 38146 Trabajadores migrantes en regiones agrícolas de exportación. Universidad Nacional del Comahue. Argentina.

${ }^{2}$ Investigadoras del GESA. Grupo.gesa@fade.uncoma.edu.ar.
} 
the influence of Southern Argentina, word market oriented, with high requirements of seasonal migrants and opacity in the records and social images. From a critical social science by breaking the obvious, we proceed to build data and findings in order to denaturalize representations and to dissect situations through the combination of methodological procedures. The purpose of this paper is therefore to show the theoretical and methodological decisions underlying in the research and to respond with substantive content and empirical inquiry to the central questions about seasonal migration in a fruit production chain.

KEYwORDs: intensive agricultural enclaves, seasonal workers, migrations, food globalitation.

\section{SUMARIO}

1.Introducción. 2.La pregunta de investigación. 3.Tematización y propuesta. 4.Desarrollos teóricos. 5. E1 contexto de la migración estacional: áreas de destino y de origen. 6.Construcción social de los datos. 7.Hallazgos empíricos y reflexión analítica. 8.A manera de cierre.

\section{SUMMARY}

1.Introduction. 2. The research question. 3. Problematization and proposal. 4. Theoretical developments. 5. The context of seasonal migration: areas of destination and of origin. Social. 6. Social construcción of data. 7. Empirical findings and analytical reflections. 8. Conclusions. 


\section{INTRODUCCIÓN}

"En calidad de cientistas sociales trabajamos siempre en un espacio social. Donde quiera que estemos como seres sociales, nuestro trabajo se da en un espacio de nuestra imaginación intelectual y en un espacio de investigación empírica. La práctica de nuestro medio y de nuestro tiempo tiende a tomar ese espacio evidente por si mismo 'natural', por eso acarrea la ausencia de reflexividad social, lo que la enflaquece, debilita y toma estrecho el análisis" (Theborn, 2006: 77). Las palabras de Goran Theborn nos alertan sobre el desafío cognitivo en las ciencias sociales a nivel mundial, e impregnan nuestra mirada sobre un viejo tema que ha tenido opacidad histórica: la migración estacional de trabajadores agrícolas.

En el campo de los estudios rurales, algunas cuestiones ocupan la atención creciente de los cientistas sociales, tales como aquellas referidas a la comprensión de las nuevas relaciones entre la intensificación de la agricultura y del trabajo, al doble desplazamiento del capital y del trabajo; así como las que manifiestan la coexistencia de formas modernas y no modernas en los procesos y ambientes de trabajo rural (Bendini y Lara, 2007). En el contexto actual de mundialización en América Latina con rasgos de modernización "conservadora" (Chonchol, 1996), concentrada y excluyente (Murmis y Bendini, 2003), surge un interés renovado en estudiar la movilidad estacional agrícola, en diferenciar situaciones, contextos, comportamientos y lógicas de los sujetos migrantes.

En este marco, presentamos la reconstrucción teórico-metodológica de una línea de investigación que se inició hace algo más de una década en el Grupo de Estudios Sociales Agrarios, sobre trabajadores golondrinas $^{3}$ en el norte de la Patagonia, Argentina, en una cadena agrícola de alto dinamismo. El propósito planteado fue indagar acerca de imágenes naturalizadas que expresan la escasa relevancia social de la migración temporal, la homogeneidad de los sujetos que la asumen y la reducción de la diversidad del fenómeno.

En otras palabras, la propuesta comienza con un cuestionamiento de lo natural, de lo obvio (Barreiro, 1975) respecto de los trabajadores golondrinas y de la territorialidad del trabajo para avanzar en el conocimiento del carácter que asume el fenómeno migratorio a través de su desmenuzamiento analítico. Los estudios regionales realizados hasta el momento dan cuenta de su presencia recurrente y creciente desde el inicio de la actividad productiva, fruticultura de peras y manzanas. La movilidad del trabajo resulta una estrategia histórica redefinida tanto por los productores y empresas como por los trabajadores en un contexto de crecientes desafíos para los sectores subalternos en las cadenas productivas.

Mostramos la complejidad conceptual del fenómeno y la trayectoria de investigación, también algunos hallazgos recientes acerca de los condicionamientos que orientan objetivamente la movilidad tanto en las áreas de origen como de destino, la caracterización del sujeto social migrante y el sentido que le otorga al movimiento. Focalizamos en las áreas nuevas de desarrollo productivo que atraen y concentran la mayor presencia de migrantes, particularmente en cosecha.

En síntesis, este trabajo tiene un doble objetivo. Por un lado, reconstruir a manera de trastienda (Wainerman y Sautu, 1997) el marco teórico metodológico y los caminos recorridos en el desarrollo empírico de la investigación desde el posicionamiento gnoseológico que considera todo acto de investigar como un proceso que integra simultáneamente lo empírico y lo teórico (Mora y Araujo, 1980, Bourdieu, 1999). Por otro lado, presentar los avances actuales de una investigación sobre trabajadores estacionales de una cadena agrícola trasvasando los ejes: perfil del trabajador, contextos de la movilidad, y significado de la práctica migratoria; es decir, poner en escena a los sujetos sociales que asumen la movilidad temporaria.

\section{LA PREGUNTA DE INVESTIGACIÓN}

Como mencionamos, uno de los propósitos de este trabajo es mostrar las decisiones teórico-metodológicas que subyacen en un estudio de migración estacional en una región agrícola de exportación. Partimos desde la opacidad local y regional del fe-

\footnotetext{
${ }^{3}$ Término utilizado a nivel nacional que refiere a los trabajadores migrantes estacionales extrarregionales, también conocidos como temporarios, boias frías, jornaleros, en otras regiones de América Latina.
} 
nómeno, el trabajador golondrina también designado como afuerino (de afuera, extralocal). La indagación central es acerca de quiénes migran (sujetos), por qué (contextos y sentido del desplazamiento) y para qué (función). La investigación empírica se sitúa en el marco de modernización flexible de las últimas décadas, siendo la unidad de análisis el trabajador golondrina. El conocimiento de sus características sociodemográficas y el significado social del desplazamiento, entendemos coadyuvan, junto a las condiciones macro estructurales y contextuales, a la comprensión de la opción familiar asumida de migrar como experiencia próxima (Seefoó, 2006).

En este sentido, y tal como señala Murmis (1991), consideramos relevante conocer los mecanismos que construyen las unidades domésticas en un tiempo y lugar concretos, para reproducir sus condiciones de trabajo y de vida relacionando sus capacidades internas en tanto contribuciones de fuerza de trabajo articuladas con las demandas de la economía capitalista (Álvaro, 2008). Algunos de estos mecanismos -como el caso de la movilidad estacional- son parte de la historia del desarrollo regional e integran y forman parte de las pautas de organización familiar, de sus estrategias de reproducción.

La explicitación de las hipótesis de este trabajo permite recorrer el camino en la construcción social de los datos. La primera hipótesis postula que frente a la escasez o ausencia de trabajo remunerado en el espacio de localización o de residencia habitual y ante los requerimientos crecientes de mano de obra en áreas agroexportadoras y nuevas en expansión, los trabajadores despliegan estrategias heterogéneas que incluyen prácticas migratorias y trabajos concretos en destinos lejanos, entre otras. La segunda hipótesis enuncia que las movilidades territoriales expresan conductas y sentidos diversos según tipos de sujetos sociales involucrados. La tercera plantea que esos comportamientos espacialmente orientados por la demanda pero también por las capacidades, disponibilidades y redes socioculturales, son resultado complejo de condicionamientos estructurales y microsociales.

\section{TEMATIZACIÓN Y PROPUESTA}

La tematización particular de esta ponencia podemos sintetizarla en las respuestas a preguntas teóricometodológicas, tal como propone Vasilachis (1993):

\section{¿Desde dónde?}

Adoptamos un enfoque que interpreta el cambio contemporáneo como resultado de un proceso histórico social, asumiendo desarrollos complejos y diversos a nivel de escala y de territorio. Un rasgo que se señala es el doble desplazamiento que se produce en la redistribución espacial y organización de la producción: por un lado, del capital productivo hacia zonas en donde la mano de obra es barata y, por otro, de la mano de obra barata hacia los lugares donde está instalado el capital productivo. Cualquiera sea la situación, los desplazamientos de trabajadores tienden a limitar aún más las posibilidades de organización y afiliación sindical. Asimismo, la organización del trabajo en las cadenas productivas modernas se configura bajo condiciones de intensificación y/o de movilidad del trabajo (Bendini, 2007).

Nos situamos en el estado del arte de los estudios sobre las migraciones internas en Argentina, desde las tematizaciones y trayectorias académicoinstitucionales ${ }^{4}$ tal como plantean Benencia (2001: 3) cuando enuncia la necesidad de "la actualización de un fenómeno que persiste", y Neiman en García Barlet (2002) al destacar la relevancia de la migración agrícola estacional como "un fenómeno en ascenso" en la Argentina.

\section{¿Qué?}

Más allá de visiones establecidas en torno a la movilidad estacional y más allá de imágenes naturalizadas acerca de los trabajadores golondrinas. Centramos nuestra mirada en los migrantes y su grupo familiar, en sus inserciones y ocupaciones, trabajos concretos, características sociodemográficas, condiciones y ambiente de trabajo en origen y destino, sentido de los desplazamientos y estrategias laborales.

\footnotetext{
${ }^{4}$ CEIL- CONICET, CENEP, FLACSO, UBA, UNCo, entre otras.

${ }^{5}$ Para ampliar aspectos referidos a la línea de investigación ver Bendini, M.; Radonich, M. y Steimbreger, N. 1999. "Historia de la vulnerabilidad social de los 'golondrinas' en la cuenca frutícola del río Negro”. En M. Bendini, y M. Radonich (comp.) De
} 
Con herramientas conceptuales apropiadas inicialmente, nos posicionamos para avanzar en el conocimiento del carácter del movimiento territorial y de la práctica migratoria como de los sujetos sociales que los asumen. Organizamos el texto, presentando luego los aportes de la investigación empírica de esta línea de trabajo; y por último, mostrando los hallazgos más recientes.

Así, pasamos revista y actualizamos el perfil y la tipología de migrantes. Nos detenemos en los contextos de origen de los migrantes cuyas características socioeconómicas han estimulado históricamente procesos migratorios de tipo estacional, y en el contexto de destino, en tanto área agrícola dinámica y en expansión, demandadora de mano de obra extralocal, especialmente para la cosecha de fruta. También indagamos en la práctica migratoria que despliegan los trabajadores y el significado de esa conducta.

\section{¿Dónde?}

El estudio se centra en una cadena frutícola de exportación de extenso desarrollo histórico y espacial con consecuencias importantes en torno a los requerimientos de mano de obra agrícola: la fruticultura de pepita (manzanas y peras). El área de origen que prevalece actualmente en la migración estacional es el noroeste argentino, en especial las provincias de Tucumán y Santiago del Estero, y el área de destino: la cuenca frutícola del río Negro en el norte de la Patagonia, en especial las nuevas zonas de expansión con organización empresarial y a escala: valles medios de los ríos Neuquén (El Chañar) y Negro (Valle Medio).

El estudio acotado a un espacio geográfico, entendemos no implica un recorte arbitrario de los procesos o del espacio social que construyen los actores y sus relaciones. Más bien intentamos centrar el análisis en un punto de anclaje local donde los rasgos temáticos se presentan más claramente destacados.

\section{¿Cómo?}

La complejidad territorial (espacial, temporal y ocupacional) que presenta la migración estacional requiere de nuevos marcos conceptuales y metodológicos que permitan desvelar estos desplazamientos transitorios $\mathrm{u}$ ocasionales invisibles para las estadísticas tradicionales como son los censos de población y las encuestas permanentes de hogares. En este sentido, las fuentes de información primarias: encuestas y entrevistas, los relatos de vida y las historias laborales, aparecen como instrumentos fundamentales que revalorizan la perspectiva de los actores para quienes volver a partir representa la estrategia de reproducción social, o una opción de mejorar sus condiciones de vida (Bendini y Steimbreger, 2008). La unidad de análisis es el trabajador migrante estacional que se desplaza a las nuevas áreas de expansión. Las unidades de relevamiento son esos trabajadores y sus familias.

La estrategia metodológica se basa en la triangulación de fuentes de datos, de procedimientos (extensivo, tipológico, unitario) y de técnicas cuantitativas y cualitativas de recolección y análisis de datos. Como expresa Bonaudo (2007) consideramos importante trabajar desde otras maneras de mirar que nos permiten recuperar las diversas tramas relacionales que se estructuran, favoreciendo $\mathrm{u}$ obstaculizando comportamientos; en este caso, no sólo desde los condicionantes y contextos de la migración, sino recuperando su interioridad y sus significados.

El abordaje empírico implica el desarrollo de distintos momentos que integran dialécticamente los niveles de análisis macro estructural y microsocial. La combinación de abordajes y de técnicas en etapas sucesivas (Gallart, 1992) dota al estudio de una doble aproximación, documental y vivencial; como también cuantitativa y cualitativa:

1.- análisis de datos secundarios documentales (censos, encuestas, informes, publicaciones, artículos de diarios, documentos históricos). Luego de analizar la información secundaria, previo control de consistencia y comparabilidad de las fuentes, procedimos a la elaboración del diseño muestral para la recolección de los datos primarios. Siguien-

golondrinas y otros migrantes. Cuaderno GESA 2, La Colmena. Buenos Aires. Bendini, M.; Radonich, M. y Steimbreger, N. (2001). "Los trabajadores agrícolas estacionales. Marco teóricoMetodológico para un estudio de caso". En Estudios Migratorios Latinoamericanos, $\mathrm{N}^{\circ} 47$, vol. 16, n 47, abril 2001. CEMLA. Buenos Aires. 
do la clasificación de Galtung (1978) optamos por un muestreo de escalón múltiple (por conglomerado, por cuotas, e intencional en el último escalón) a migrantes estacionales de grandes empresas frutícolas en áreas de expansión productiva: El Chañar, en la provincia de Neuquén, y Valle Medio, en la provincia de Río Negro.

2.- encuestas y entrevistas semiestructuradas con observación en terreno en lugares de destino, ${ }^{6} \mathrm{y}$ entrevistas a informantes claves del ámbito público y privado (personal jerárquico de las empresas, productores, funcionarios y técnicos del sector público, dirigentes gremiales, entre otros) que permitieron enriquecer la información anterior. El primer trabajo de campo se realizó en la temporada 2001/2002. El análisis agregado de los datos provenientes de las encuestas se complementó con la información de las entrevistas, lo cual permitió trazar el perfil sociodemográfico de los trabajadores golondrinas, precisar sus condiciones laborales y ambientes de trabajo y de vida, y construir una tipología de migrantes estacionales en base a su inserción y trayectoria ocupacional, el origen y dirección de la movilidad y los condicionantes del movimiento. Es decir, no sólo mostramos al trabajador migrante en tanto sujeto social agrario sino también en su diferenciación social, la que expresamos en cuatro tipos de migrante como reducción de la complejidad del fenómeno y de la diversidad de situaciones. El segundo trabajo de campo realizado en la temporada 2007/2008, permitió actualizar y profundizar el perfil sociodemográfico, las condiciones laborales y de vida en lugar de destino y redefinir la tipología de migrantes estacionales. A su vez, los datos sirvieron de base para la selección de una muestra por cuotas: edad, temporadas realizadas, nivel de instrucción, tipo de residencia habitual a los fines de entrevistar al migrante y familia en sus lugares de origen.
3.- realización de entrevistas semiestructuradas a trabajadores golondrinas y a sus familias en los lugares de origen (provincias de Tucumán y Santiago del Estero) en mayo de 2008. ${ }^{7}$ En este relevamiento hicimos hincapié en la dimensión diacrónica que permite el análisis de la trayectoria migratoria en las configuraciones históricas a nivel individual, familiar y de la comunidad. La información primaria obtenida a través de estas entrevistas se complementó con otras técnicas cualitativas de recolección, tales como observación etnográfica y entrevistas con bajo grado de estructuración dirigidas a intermediarios/enganchadores en áreas de origen (transportistas, líderes, dirigentes sindicales y funcionarios/técnicos del ámbito público) vinculados con el fenómeno migratorio.

4.- estudio instrumental de caso (Stake, 2005) a través de los relatos de vida de una familia tucumana y de una familia santiagueña cuyas trayectorias migratorias involucran tres y dos generaciones respectivamente. Actualmente estamos abordando la relación entre historia laboral, desplazamientos territoriales y dinámica familiar de los casos seleccionados; uno de ellos considerado paradigmático a nivel nacional en la década de los años '70: la familia Reales. El seguimiento de las trayectorias migratorias de dos familias con distintos proyectos migratorios permitirá la comprensión de las estrategias de vida y del significado del desplazamiento, vinculando condiciones estructurales contextuales y micro sociales. Este procedimiento se sustenta en la necesidad de superar el concepto de individuo migrante para resituar al trabajador golondrina en el contexto familiar, colectivo y comunitario.

\section{¿Por qué y para qué?}

Dada tanto la naturalización del fenómeno y la escasez de registros sobre la persistencia y relevancia social como, más recientemente, el incremento del volumen de migrantes estacionales en la cadena,

\footnotetext{
${ }^{6}$ En la temporada 2001/2002, se aplicó una encuesta en el Valle Medio de Río Negro a 61 trabajadores migrantes estacionales. Se entrevistaron trabajadores golondrinas en las principales localidades que reciben mayor flujo migratorio (Lamarque y Chimpay) y en 7 empresas de la región, las cuales contratan mayores volúmenes de migrantes estacionales (muestreo por escalón múltiple intencional y por cuota). En la temporada 2007-2008, se realizaron 30 entrevistas con bajo nivel de estructuración. En la temporada 2006/2007 se aplicaron encuestas a 250 trabajadores golondrinas en El Chañar, 35 entrevistas en profundidad durante la temporada 2007-2008. Proyectos GESA 037, FADECS, Universidad Nacional del Comahue y GESA-ANPCyT PICT 38146.

${ }^{7}$ En la provincia de Santiago del Estero se realizaron entrevistas a migrantes y su grupo doméstico en las localidades de Termas de Río Hondo, Colonia Tinco, Paraje Mansupa, Paraje Acos. En la provincia de Tucumán en las localidades de León Ruges, Asentamiento Mercedes, Amberes, Villa Quinteros y Acheral, Famaillá, Barrio el Cruce y la Reducción. Proyecto GESA-ANPCyT 38146.
} 
nos interesa ampliar su visibilización social, profundizar el conocimiento de su conducta y el sentido vivenciado, brindar elementos para redefinir la imagen social e institucional de estos trabajadores y sus familias. También resignificar el desplazamiento en el contexto social, y contribuir para una mayor intervención en materia de políticas activas y protectorias del campo laboral.

\section{DESARROLLOS TEÓRICOS}

Hablar de migración y de movilidad territorial de la población significa introducirnos en un debate complejo y de actualidad en los estudios rurales a propósito de la expansión del gran capital y sus efectos en la estructura social. Abordamos en la investigación, la caracterización de contextos y de sujetos para la comprensión de dinámicas y posicionamientos migratorios. Para ello, revisamos al respecto aportes significativos de algunos autores contemporáneos.

En América Latina los estudios sobre movimientos temporales o estacionales de trabajadores tienen una trayectoria significativa dada la relevancia que este fenómeno ha tenido y sigue teniendo en la región. Se inician en la década de los setenta cuando todavía el interés teórico y los estudios empíricos estaban centralizados en las migraciones rurales urbanas más o menos definitivas asociadas al proceso de urbanización. Los numerosos trabajos que se desarrollan a partir de entonces bajo la perspectiva histórico-estructural permitieron por un lado, conocer con mayor especificidad esos movimientos temporales, en especial aquellos que complementan actividades agrícolas en diferentes espacios rurales. Por otro, demostrar la complejidad social de estas formas de movilidad refutando la hipótesis generalizada de que representaban un paso intermedio hacia la migración definitiva.

Como muestran los trabajos, los desplazamientos temporales constituyen un patrón histórico que tiene su raíz en el surgimiento del trabajo asalariado vinculado con la demanda de mano de obra para las tareas de zafra y cosecha en las explotaciones agrícolas capitalistas. En esta línea se pueden citar, entre otros, los trabajos de Sabalain y Reboratti (1980), Reboratti (1983) sobre migraciones temporarias en nuestro país; de Rodríguez y Venegas (1986) quienes realizaron un análisis sobre campesinos migrantes temporales en la región de Morelos, México; de Palau y Heikel (1986) que estudiaron los desplazamientos espaciales temporales en el este paraguayo. Investigaciones realizada sobre esta temática se expusieron, en ese entonces, en el Seminario sobre Migraciones en América Latina (Quito, 1984), cuyos trabajos se publicaron dos años después en el libro ...Se fue a Volver, marcando un hito en la investigación sobre desplazamientos temporarios de trabajadores agrícolas.

En nuestro país han sido numerosos los estudiosos de la migración y de la movilidad territorial de la población desde diferentes disciplinas científicas y propuestas teórico-metodológicas (Forni, Benencia y Neiman, 1991; Benencia, 2001), algunos más centrados en cadenas y áreas de producción en fresco como los de Benencia y Quaranta (2001), Tadeo y Palacios (2004), entre otros. La mirada institucional en los últimos años da cuenta de algunas experiencias de conexión estado-aparato científico técnico y organizaciones sindicales; ${ }^{8}$ con el propósito de elaborar diagnósticos y coordinar acciones para el diseño de políticas, aún sin continuidades sistemáticas pero con mayor eficacia en las respuestas. En el norte de la Patagonia y desde una perspectiva macroestructural y microsocial que conecta los estudios sobre migraciones estacionales con la historia agraria de la región, mencionamos especialmente los trabajos realizados por investigadores del departamento de Geografía y del Grupo de Estudios Sociales Agrarios de la Universidad Nacional del Comahue. ${ }^{9}$

En las últimas décadas del siglo XX y principios del actual, los movimientos estacionales de trabajadores agrícolas no sólo siguen teniendo vigencia sino que algunos estarían adquiriendo mayor inten-

\footnotetext{
${ }^{8}$ En 2007 el Ministerio de Trabajo, Empleo y Seguridad Social organizó la Primera Jornada Nacional sobre Trabajo Migrante Estacional Agrario. Participaron instituciones sindicales y de seguridad social como OSPRERA, RENATRE, UATRE, Secretaría de Trabajo de las provincias de origen y destino de los migrantes estacionales, Cámaras de Productores, Cámara de Fruticultores Integrados y Universidades Nacionales. En 2009 Taller sobe Migraciones en Cervantes y en Roca (Alto Valle) organizados por el estado provincial y organizaciones locales.

${ }^{9}$ Ver Kloster et al (1992); Riffo et al (1997); Bendini et al (1999).
} 
sidad y diversidad a partir de las nuevas formas de organización productiva de la agricultura, las cuales obviamente afectan al mercado de trabajo rural. En este sentido, es necesario aclarar que la tendencia de las empresas agroalimentarias es mantener un reducido número de trabajadores permanentes polivalentes y calificados, y aumentar la demanda de trabajadores temporarios menos calificados para la ejecución de tareas puntuales acentuando la flexibilidad laboral que desde siempre caracterizó a la actividad agropecuaria (Kloster, Radonich, Steimbreger et al, 1998).

Tradicionalmente los requerimientos estacionales del sector agrícola fueron cubiertos por migrantes provenientes de áreas rurales, sin embargo, algunos autores advierten sobre la presencia de mano de obra temporal con residencia urbana y diferentes grados de calificación. Son conocidos los movimientos temporarios de los boias frías en Brasil, trabajadores asalariados rurales que viven en las periferias de las ciudades y son contratados por un tiempo determinado para tareas de cosecha.

La magnitud y heterogeneidad que presentan estos desplazamientos temporales en las últimas décadas es resultado de la interrelación de diferentes factores entre los que se pueden mencionar, las nuevas condiciones de los mercados de trabajo, los efectos residuales de las medidas de ajuste estructural y de flexibilidad laboral, la incorporación creciente de tecnología de punta en sectores agroexportadores y la incorporación de adelantos en el transporte y las comunicaciones. Recogemos a continuación algunos aportes conceptuales pertinentes a esta línea de investigación,

\section{Movilidad territorial de la población}

La producción científica sobre migración más reciente ha logrado superar las limitaciones conceptuales y metodológicas de los abordajes clásicos para interpretar las diversas formas de movilidad territorial de la población. A partir de este cambio que puede interpretarse como una ruptura epistemológica, la definición tradicional de migración queda limitada a un tipo particular de desplazamiento (cambio de lugar de residencia habitual) y se diferencia de los movimientos temporarios, circulares, pendulares, estacionales. La migración queda incluida dentro de un fenómeno más amplio que pasa a denominarse movilidad territorial, definida como todos aquellos "fenómenos relacionados con el desplazamiento geográfico o territorial de los individuos que componen una población" (CENEP, 1995: 6). Implica moverse en espacios multiformes y cada vez más dilatados; desde desplazamientos cotidianos hasta estadías de larga duración, desde trayectorias migratorias hasta comportamientos ocasionales ${ }^{10}$ (Domenach y Picouet, 1995).

$\mathrm{Al}$ interior de este abanico de movimientos territoriales, la migración estacional no implica una ruptura entre el lugar de origen y de destino, aunque existe un período de ausencia del lugar de residencia habitual que puede ser muy variable. El migrante estacional o temporario siempre vuelve a su lugar, a su espacio de pertenencia social. La complejidad que caracteriza a estos movimientos permite diferenciarlos según se inserten en circuitos migratorios que articulan diferentes áreas productivas o si se realiza entre el lugar de origen y un destino particular.

En tal sentido, al referirse a los movimientos estacionales, Sara Lara (2006a), distingue por un lado, la migración de tipo circular que involucra más de dos lugares de trabajo, con el lugar de residencia en las áreas de origen; movimiento que se puede asociar al concepto de nomadismo laboral ${ }^{11}$ (Pedreño, 1999). Estos circuitos están íntimamente relacionados con la dispersión geográfica de las empresas y el carácter transitorio/estacional del empleo que generan. Por otro lado, la autora identifica la migración pendular que tiene lugar entre el lugar de origen y el lugar de destino o área de trabajo, para regresar nuevamente al primero. Asimismo, la descentralización geográfica de las empresas provoca el intercambio de mano de obra estacional entre las diferentes explotaciones dentro de la misma región o entre regiones y aún países. Estas estrategias empresariales

${ }^{10} \mathrm{Al}$ respecto, ver Bendini, M.; Steimbreger. N. y Radonich, M. 2008. "Continuidades y cambios en la migración estacional" Ponencia presentada en Seminario CEMLA, CEIL-UBA, Buenos Aires.

${ }^{11}$ El nomadismo laboral es una forma de movilidad de los individuos y grupos sociales como una opción de trabajo. Su diferencia con respecto a la migración tradicional reside en que no se trata de una movilidad afirmada en un cambio de residencia, por el contrario, el nomadismo laboral es una movilidad que lleva implícita una "lógica de retorno al hogar" (Pedreño, 1999). 
han tenido un efecto importante en los mercados de trabajo agrario y en los ciclos migratorios de los trabajadores estacionales. La articulación entre áreas y actividades productivas genera circuitos migratorios o pendulares de duración variable que no llegan a constituir cambios definitivos de residencia y que asumen significado social por su rol en las estrategias de reproducción social (Bendini y Steimbreger, 2008; Radonich y Steimbreger, 1996).

El término teórico espacio de vida completa el de desplazamiento porque delimita el espacio en el que se realizan todas las actividades, puede tener un sentido amplio si se tienen en cuenta todas las conexiones del individuo, o restringido si solo retenemos el lugar de residencia de la familia y el del trabajo. Tradicionalmente la noción de residencia única definía el carácter de la movilidad; sin embargo, la multiplicidad de trayectorias y de su duración redefine el concepto ya que diminuye la importancia de la residencia única. Emergen categorías nuevas tales como residencias principal, secundaria, múltiples, ocasionales, sucesivas. Se produce a su vez un cambio en la naturaleza del concepto, algunos autores incorporan el concepto de residencia base ${ }^{12}$ que permite introducir la noción de reversibilidad de los flujos migratorios, desplazamientos múltiples, formas del movimiento y circuitos, que dan cuenta de la heterogeneidad de prácticas y complejidad de la movilidad territorial. "Las fluctuaciones periódicas o estacionales, las estadías ocasionales (aún de varios meses) carecen de consecuencias grandes en las vidas de los individuos y de sus familias, ni tampoco modifican casi su distribución espacial, aún cuando esta movilidad temporaria puede llevar consigo una progresiva modificación del espacio de vida inicial" (Domenach y Picouet, 1995:13).

Otros autores incorporan los conceptos de territorios migratorios y de proyectos migratorios. Como expresa Lara $\left(2006^{\mathrm{a}}\right)$, las desigualdades regionales y la jerarquización de los territorios intensifican los desplazamientos migratorios de trabajadores, $\mathrm{y}$ estimulan un encadenamiento de movimientos a diferentes escalas geográficas: locales, regionales, nacionales e internacionales. Dentro de este complejo fenómeno social, las migraciones estacionales entre regiones al interior de las fronteras regionales, con diferentes dinámicas productivas, "operan como vasos comunicantes, conectando espacios (...), suscitando nuevas configuraciones y nuevos agentes territoriales, así como nuevos tipos de actores sociales (en el campo laboral político, económico y cultural)" (Lara 2009: s/e).

\section{Estrategias de reproducción social}

Aunque los desplazamientos estacionales responden a un patrón histórico que tiene sus raíces en el surgimiento del trabajo asalariado, actualmente son resignificados por su rol en las estrategias de reproducción social, en especial, en los países subdesarrollados. El concepto de reproducción social es amplio y se puede definir como un proceso que envuelve tanto la producción como los servicios sociales y las diversas actividades de gestión de desarrollo como de planificación, de seguridad, entre otros. Esta conceptualización busca romper con la dicotomía que se da entre la economía, preocupada por producir riquezas, y lo social, que va acompañada de atraso, intentando a través de políticas de compensación reducir las contradicciones generadas como la miseria, el abandono y la exclusión (Dowbor, 2001).

Por su parte Iñaki (2008: s/e) considera como "estrategias familiares de reproducción a los planes que elaboran las familias para lograr mantener o mejorar sus condiciones de vida y/o su estatus social a lo largo del tiempo, y a las medidas de todo tipo que toman para alcanzar dicho logro. ${ }^{13}$ Como cualquier clase de estrategia, las estrategias familiares de reproducción se desarrollan en el tiempo (...) A lo largo de ese tiempo los sujetos que quieren alcanzar dicho objetivo toman medidas, emplean sus recursos y toman decisiones cuyas consecuencias pueden acercarlos o alejarlos del cumplimiento del mismo".

Torrado (1980) aborda las estrategias familiares de vida con la intención de vincular la reproducción material y biológica del grupo familiar (procreación,

\footnotetext{
${ }^{12}$ Lugar o conjunto de lugares a partir de los cuales los desplazamientos tienen una probabilidad de retorno más elevada en oposición al concepto tradicional de cambio de residencia (Domenach y Picouet, 1995).

${ }^{13}$ El autor considera el término familia o grupo familiar a la familia nuclear a la que, eventualmente, puede añadirse la pareja formada por alguno de los hijos/as; en el caso de las familias extensas utiliza la expresión grupos de parentesco.
} 
el ciclo de vida familiar, división del trabajo, organización del consumo, cooperación extrafamiliar, migración laboral). La intención de conectar la esfera de la producción y reproducción social y económica, implica la posibilidad de que las familias puedan acceder a oportunidades laborales destinadas a suministrar los medios de subsistencia. Desde esta perspectiva, las estrategias familiares de vida se refieren al conjunto de comportamientos a través de los cuales las unidades familiares o domésticas tratan de optimizar sus condiciones de vida dadas ciertas determinaciones estructurales (condición socioeconómica) y coyunturales (políticas públicas). La familia es la instancia microsocial o microdinámica que relaciona el contexto macroestructural con las decisiones y relaciones de los individuos que la componen.

Consideramos que las estrategias de sobrevivencia y prácticas de reproducción social constituyen conceptos centrales para comprender la organización y las formas de persistencia de las familias pobres. Se construyen a partir de las decisiones que garantizan la permanencia del grupo doméstico como tal, integrando espacios de localización y territorios migratorios apropiados. El concepto ayuda a describir comportamientos, interrelacionarlos e interpretarlos y puede definirse como el conjunto de acciones, económicas, sociales, culturales que realizan los estratos poblacionales que no disponen de recursos suficientes ni se incorporan plenamente al mercado de trabajo, por lo que no obtienen de las mismas actividades, ingresos regulares para mantener su existencia en un nivel socialmente determinado, dadas las insuficiencias estructurales del estilo de desarrollo predominante (Canabal y Flores: 2001).

\section{EL CONTEXTO DE LA MIGRACIÓN ESTACIONAL: ÁREAS DE DESTINO Y DE ORIGEN}

"Nadie migra porque quiere" expresa la Pastoral de Migraciones del Episcopado de Neuquén. En efecto, la falta de empleo en el lugar de residencia induce a los individuos a elaborar estrategias que incluyen una gama diversa de actividades que afectan la vida doméstica y la situación económica y social. La movilidad estacional aparece así como una de las tantas expresiones de las estrategias para lograr la sobrevivencia familiar.
Los desplazamientos espaciales pendulares y circulares responden a demandas laborales agrícolas típicamente estacionales y no implican necesariamente una ruptura entre el lugar de origen y el lugar de destino. Más allá del tiempo que dura la ausencia, el migrante temporario siempre tiene la intención de retornar a su residencia habitual. "Es la consideración de la ausencia como algo temporal. El viaje, la ida y la vuelta, no importan mayormente, lo que interesa fundamentalmente es el volver. Irse a volver" (Pachano, 1986: 20).

La comprensión de la movilidad estacional de los trabajadores agrícolas no se circunscribe solamente a las condiciones de la relación expulsión/atracción de las regiones o áreas de origen y destino, sino que abarca el desplazamiento temporario en tanto expresión social de la conducta de sujetos sociales (tipos y características) y el sentido (para el migrante y su familia) del comportamiento espacial y temporal en tanto práctica social.

\section{La región frutícola del norte de la Patagonia}

El área frutícola del norte de la Patagonia, Argentina, está integrada por la zona frutícola tradicional del Alto Valle de Río Negro y Neuquén y las nuevas áreas productivas del Valle Medio del río Negro y del valle medio-inferior del río Neuquén (El Chañar). Abarca una superficie bajo riego de aproximadamente 140.000 hectáreas, de las cuales, el 75 por ciento corresponde a la provincia de Río Negro. Los nuevos espacios de expansión frutícola representan algo más de un tercio del total de la superficie implantada; son las áreas que tienen mayores rendimientos productivos y en las que se observa un aumento continuo del volumen de fruta fresca.

Una periodización ilustrativa del desarrollo de esta cadena distingue: una etapa organizativa y de consolidación de la actividad frutícola (fines de los años treinta a fines de los cincuenta del siglo pasado) con una organización social del trabajo que combinaba trabajo familiar y mano de obra asalariada, intensificando los procesos migratorios nacionales (interior de las provincias de Río Negro y Neuquén) y transandinos (Chile); le sigue la etapa de integración agroindustrial (años sesentas y principio de los setentas) con crecimiento de la actividad de carácter más incluyente que incidió en una necesidad creciente de mano de obra estacional para cosecha y empaque que 
intensificó los flujos migratorios. Más recientemente, la etapa de concentración y transnacionalización, con modernización excluyente, expansión territorial y crecientes requerimientos de mano de obra asalariada, predominantemente en cosecha, consolidándose flujos migratorios, básicamente nacionales y provenientes del noroeste del país.

En cuanto a la composición del trabajo, los datos del Censo de Áreas bajo Riego -CENSAR- (Secretaría de Fruticultura, 2005) muestran un descenso importante de los ocupados familiares al finalizar el siglo pasado, más aún en las nuevas áreas. Los datos indican una organización empresarial del trabajo más extendida en los valles medios con aumento notorio de la mano de obra asalariada (93 por ciento del total de ocupados). Existe asimismo una mayor división jerárquica de tareas (personal administrativo, gerencial, técnico, capataces, encargados, peones rurales especializados y peones rurales generales), es decir, en las nuevas áreas productivas, el desarrollo de una matriz empresarial produjo el incremento de las relaciones asalariadas y de la demanda temporaria de trabajadores. La fuerte estacionalidad que aún caracteriza a esta fruticultura provoca altos requerimientos de mano obra, principalmente para la época de recolección de la fruta (diciembre a abril). Según estadísticas provinciales del 2005, durante el mes de mayor demanda (marzo) se contabiliza un total de 25.900 personas ocupadas en toda la cuenca frutícola. De este total, las tres cuartas partes (18.782 trabajadores) corresponden a trabajadores estacionales (locales y extrarregionales), y de ellos las tres cuartas partes son migrantes, lo cual expresa su importancia. Según estimaciones sindicales y gubernamentales en la temporada 2007/2008 ascendían a 18.000 trabajadores.

Como se señaló, la actividad demandó desde sus inicios trabajo asalariado estacional, necesidad cubierta a través de flujos migratorios recurrentes; siendo así, los trabajadores golondrinas acompañaron el desarrollo del agro regional. La complementariedad regional que se estableció a través del tiempo, entre el área centro-sur de Chile, la región del noroeste argentino y las áreas frutícolas del norte de la Patagonia, permitió no sólo que los trabajadores estacionales pudieran encadenar actividades agrícolas en distintos momentos del año, sino también que los empresarios se aseguraran la disponibilidad de mano de obra en el momento oportuno. Lara (2009) refiere a la migración por sustitución a partir de la cual los trabajadores migrantes se insertan en los segmentos del mercado de trabajo que van siendo dejados por la mano de obra local o porque son considerados de muy baja calificación. En el caso de estudio esta sustitución se ejemplifica históricamente en la migración internacional limítrofe por nacional, en la local por extralocal, y en las mujeres por hombres. A través del tiempo, la migración trasandina hacia la región fue disminuyendo hasta ser, en la actualidad, casi insignificante; este fenómeno produjo un vacío en ese espacio laboral que condujo a una reorientación de la migración estacional que proviene mayoritariamente del norte de nuestro país y, por otra parte, disminuyeron los desplazamientos de mujeres y niños (migración familiar) aunque el proceso de masculinización y el perfil etario es diferencial por zona y según variedad de la fruta.

Los empresarios y pequeños productores coinciden en que es difícil cubrir la necesidad de mano de obra estacional para la época de recolección de la fruta, siendo aún más crítico en los nuevos espacios productivos. Por otro lado, la demanda estacional de mano de obra extrarregional no solo persiste sino que se incrementa. Algunas de las razones fundamentales que explican la continuidad de los desplazamientos son: i) en la zona tradicional no se han modificado significativamente los requerimientos extralocales a pesar de los diferenciales procesos de reconversión del monte frutal. Si bien las modernas plantaciones aceleran la entrada en producción de los frutales y aumentan los rendimientos por hectárea, también es cierto que se tiende a hacer un uso más eficiente de la mano de obra, conformándose cuadrillas de cosechadores; ii) en las nuevas áreas de expansión se advierte una necesidad creciente de mano de obra estacional para la cosecha como consecuencia de la constante expansión de la superficie implantada y los crecientes volúmenes de producción que se incorporan anualmente.

Asimismo, los cambios en la demanda de trabajadores estacionales varían según tipo de explotación. El pequeño productor presenta una tendencia a contratar mano de obra local, que por otra parte se compone de una proporción significativa de antiguos migrantes estacionales chilenos radicados en la zona. En el caso de los productores medianos y de las grandes empresas, persiste y se incrementa el requerimiento de trabajadores extrarregionales, 
en particular norteños. Surgen nuevos rasgos en el perfil demandado y en el circuito espacial del trabajador golondrina, asociados a la calidad y a las buenas prácticas, a las nuevas producciones y a las áreas de exportación.

Desde otra mirada, este movimiento estacional es una parte significativa de las estrategias de reproducción familiar en los períodos de desocupación o subocupación en las áreas de origen frente a la oferta laboral que se produce en el norte de la Patagonia. En este sentido, retomamos la opinión de Neiman en García Bartelt, (www.lanacion.com.ar, 2002), quien destaca que los trabajadores golondrinas son "un fenómeno en ascenso por el crecimiento del desempleo".

\section{Área de origen de los migrantes estacionales}

Las economías regionales del noroeste $\operatorname{argentino~}^{14}$ se conformaron históricamente en base a monocultivos como azúcar o tabaco, cuya producción demandó desde sus inicios, mano de obra estacional. Este proceso implicó durante el siglo veinte, voluminosos desplazamientos de trabajadores para la época de cosecha. Sin embargo, en períodos de intercosecha se producían índices elevados de subempleo y desempleo, lo cual indujo a la búsqueda de alternativas laborales extralocales. Así, se generaron movimientos de mano de obra hacia otras regiones que requerían fuerza de trabajo estacional y con el correr del tiempo, se fueron configurando circuitos migratorios que articularon áreas productivas complementarias.

De esta manera, la migración se incorpora como estrategia de reproducción social de numerosas familias del noroeste argentino y, como plantean Giarracca et al (2001), estos movimientos estacionales fueron formando parte de las trayectorias vitales de muchas familias o de grupos de trabajadores, de tal manera, que algunos migrantes recientes que arriban al norte de la Patagonia acompañaron a sus padres y tíos en años anteriores, y más tarde, reproducen la estrategia con su propio núcleo familiar dando cuenta de la continuidad de este proceso.

Como en otras economías regionales, en la década de los noventas, se produjeron cambios importantes en la estructura y en la superficie agropecuaria del noroeste argentino como consecuencia de la fuerte expansión de los cultivos de cereales y oleaginosas, principalmente en Salta, Tucumán y Santiago del Estero (Bolsi et al, 2008). Las características que asume el rol del estado en los noventas fueron cruciales para la economía de esa región (NOA), centrada en la actividad azucarera. Esta actividad, fuertemente regulada en décadas anteriores, fue afectada por las políticas de desregulación y apertura comercial que rompen el precario equilibrio logrado entre los actores del complejo agroindustrial, los cupos de producción y las cuotas de abastecimiento del mercado interno las que se eliminaron como también se disolvió la Dirección Nacional del Azúcar. En las agroindustrias más nuevas, como la del limón, que había registrado una marcada expansión, se produjo una fuerte tendencia a la concentración ${ }^{15}$ con desplazamiento de pequeños productores. ${ }^{16}$

En el plano laboral, en esos años, se profundiza la precariedad del trabajo y la tercerización de la contratación de la mano de obra. El mundo rural fue afectado en su conjunto, pero principalmente en los sectores más subordinados: cambios en los vínculos contractuales y laborales, precarización creciente de los trabajadores dependientes del agro, expansión de la tercerización, fueron algunos de los efectos que incrementaron la marginación o la exclusión. La dinámica que asumió la estructura productiva se asoció con un fuerte proceso de urbanización que estimuló la concentración de la población en las capitales provinciales. ${ }^{17}$ Éstas se convirtieron en receptoras de una importante cantidad de la población rural que en gran parte se estableció en condiciones precarias.

${ }^{14}$ El área del noroeste argentino (NOA) está integrada por las provincias de Jujuy, Salta, Tucumán, Santiago del Estero, Catamarca y La Rioja.

${ }^{15}$ A mediados de los años setenta, el 50 por ciento de la producción de limón en Tucumán era comercializado por sólo 13 explotaciones de las 520 que existían en ese momento (Alfaro y Berenguer, 2003).

${ }^{16}$ Según los censos agropecuarios, entre 1988 y 2002 hubo una gran disminución de las explotaciones agropecuarias de menos de 5 hectáreas, cifra cercana al 20 por ciento del total inicial. Aún cuando estos procesos variaron de provincia en provincia, en su conjunto señalan el rumbo general de las transformaciones agrarias de esa década, hacia el incremento de grandes explotaciones.

${ }^{17}$ Más del 78 por ciento vive en localidades urbanas con alta concentración en las capitales provinciales, Tucumán 79 por ciento de la población, y Santiago del Estero 66 por ciento. 
El área comprendió en el pasado y aun en la actualidad, espacios de diversidad y de intensa interculturalidad. Se puede distinguir la coexistencia de dos grandes conjuntos. Por un lado, el integrado por la sociedad moderna, en la que el capitalismo desempeña un papel central que se expresa en el desarrollo de los complejos agroindustriales (azúcar en Tucumán, Salta y Jujuy; forestal y ganadero en Santiago del Estero). La localidad de Monteros, área de origen de numerosos migrantes que arriban a la región frutícola del norte de la Patagonia, representa un ejemplo de consolidación del capitalismo a través de complejos agroindustriales ligado al mercado interno con crisis de sobreproducción y nuevas formas de regulación, lo cual condujo a una fuerte expulsión de población y al desarrollo de estrategias históricas de migración estacional. La multiplicación de cultivos de riego con tecnologías de punta, el avance de la producción citrícola, nuevos cultivos como la soja o la pecuarización creciente, la forestación, o las actividades mineras y turísticas, no lograron alterar el esquema de debilidad productiva y de escasa participación de la región en la economía nacional.

Sin embargo, la consolidación del capitalismo coexiste con la persistencia de una sociedad tradicional, caracterizada por relaciones conservadoras paternalistas vinculada con el mundo campesino e indígena.. Nos encontramos con áreas con alta proporción de población indígena o de población criolla en las que las prácticas dominantes se vinculan con la producción de autoconsumo y la venta temporal de fuerza de trabajo. Esta diversidad se expresa en la distribución del ingreso y en la calidad de vida de la población.

En este sentido, son las poblaciones rurales del NOA las que presentan peores condiciones de vida del país: hacinamiento, carencia de infraestructura, déficit educativo, trabajo inestable y sin cobertura social, mayor riesgo de muerte infantil, formando parte de sus penurias cotidianas (Velázquez y Vega, 2008; Bolsi et al 2008), a pesar de haber superado los niveles de décadas anteriores. Este mejoramiento relativo se debe en parte, a las políticas públicas más recientes orientadas a mejorar los índices de mortalidad infantil, los niveles de alfabetización y las condiciones de las viviendas.

\section{CONSTRUCCIÓN SOCIAL DE LOS DATOS}

\section{Tipología de trabajadores golondrinas}

Los cambios recientes observados en el perfil sociodemográfico y en la inserción laboral, nos conducen a redefinir la tipología de trabajadores migrantes que construimos hace más de quince años. Más específicamente, la información relevada en las áreas de origen nos ha permitido revisar esa primera tipología basada en la información recolectada en áreas de destino.

En los periodos de consolidación y expansión agroindustrial prevaleció el tipo Semi asalariado rural que combina el trabajo en la parcela con la venta de trabajo extrapredial. Puede ser pequeño productor campesino o bien, involucra a aquellos miembros de la unidad doméstica que ofrecen su fuerza de trabajo fuera de la explotación. Era el migrante proveniente principalmente de Chile y en menor medida, de Tucumán, cuya residencia era rural. La menor presencia de trabajadores estacionales trasandinos, y los efectos del proceso de modernización conservadora que trajo como consecuencia la disminución de campesinos y minifundistas cañeros, condujo a una menor relevancia de este tipo de migrante. En la actualidad, se circunscriben más a los migrantes santiagueños que poseen pequeñas parcelas destinadas casi exclusivamente a la subsistencia.

A partir de la fase de expansión concentrada fueron adquiriendo relevancia los tipos Asalariado rural con pluriactividad de base agraria y Asalariado urbano con pluriactividad multisectorial.

El primero combina dos o más ciclos productivos a lo largo del año articulando diferentes espacios. Rotación entre empleo y empleadores. Este tipo de migrante se asocia a las categorías migración de tipo pendular o circular (Lara, 2006a) o nomadismo laboral (Pedreño, 1999). Se trata de trabajadores provenientes del noroeste argentino, predominantemente de Tucumán, que durante los años noventa poseían residencia urbana y periurbana, ${ }^{18}$ principalmente. Una característica reciente y novedosa es que

\footnotetext{
${ }^{18}$ En este caso, la movilidad se relaciona con las características estacionales de la actividad productiva del área de origen y la ausencia de alternativas laborales el resto del año. Este desplazamiento es asumido como una estrategia histórica de reproducción social incorporada al modo de vida del trabajador y su familia.
} 
gran parte de estos migrantes norteños provienen de áreas suburbanas (asentamientos), de pueblos o parajes rurales, lo cual estaría relacionado con un paulatino despoblamiento de las zonas rurales de población dispersa, la mayor necesidad de fuerza de trabajo estacional en estos complejos agroexportadores y el incremento de las tasas de desempleo urbano. El segundo combina tareas urbanas de carácter ocasional y/o temporario, principalmente en servicios (albañilería, quioscos, hotelería, restaurantes, venta de ropa, taxistas, etc.) e industrias (empaque de cítricos, frutilla, etc.) con trabajo agrícola estacional. Migrante estacional proveniente del norte, con residencia urbana y periurbana. También está asociado a circuitos migratorios, incluyendo diferentes áreas y ocupaciones agrícolas / urbano-turísticas.

Durante los ochentas y parte de los noventas, tuvo presencia un sujeto social regional que se inserta como asalariado agrario ocasional y/o temporario. Su participación se desvanece en el siglo actual por mejoramiento de las condiciones productivas y de empleo en zonas rurales dispersas y aglomeradas de ganadería extensiva. Se trata del tipo Desocupado en áreas de origen, asalariado urbano tradicional en sector servicios. Este migrante estacional proveniente de la Línea Sur rionegrina, Sierra Colorada y Viedma con residencia urbana, representa una fuerza de trabajo de reserva que depende de los vaivenes del mercado laboral local. Se insertan en la actividad frutícola en momentos de crisis del trabajo regional. En general, no tienen tradición/trayectoria migratoria tal como ocurre en los otros casos.

La tipología expresa por un lado, la persistencia de la condición diferencial permanente de pobreza al interior de esta fuerza de trabajo y, por otro, la diversidad y el aumento de la complejidad de este grupo aparentemente homogéneo.

\section{Perfil sociodemográfico}

La nueva organización de los procesos de trabajo requiere de perfiles más versátiles y flexibles dando lugar a un incremento de las inserciones en el mercado laboral de tipo transitorias y discontinuas. Las transformaciones en la demanda de trabajo y las facilidades ofrecidas por los sistemas de comunicación y de transporte, permeabilizan las fronteras político-administrativas, aumentando los desplazamientos territoriales de trabajadores.

Los migrantes golondrinas que arriban para trabajos concretos en la producción en fresco en las nuevas áreas de producción de la cuenca son, en general, jóvenes adultos cuyas edades oscilan entre 25 y 40 años; esta especificidad etaria es una de las características que no se ha modificado a través del tiempo a diferencia de trabajadores golondrinas de décadas anteriores y de aquellos que llegan a los valles tradicionales quienes presentan un rango mayor xon predominio de adultos. Existe una clara hegemonía de trabajadores proveniente del noroeste, principalmente de Tucumán y de Santiago del Estero, en especial, de pueblos y parajes rurales de esas provincias.

Uno de los cambios más relevantes en los flujos migratorios estacionales está vinculado con el origen. A partir de la década del noventa, la histórica participación de la mano de obra estacional chilena en la recolección de la fruta disminuye significativamente al tiempo que aumenta la presencia de trabajadores estacionales norteños (del norte argentino, término que incluye encubierto a trabajadores bolivianos). Este fenómeno está íntimamente vinculado con los cambios económicos producidos en los contextos de origen como también con las transformaciones ocurridas en el conjunto de la actividad frutícola de la cuenca.

Respecto del nivel de instrucción de los migrantes, se observa un aumento en los años de escolaridad, lo cual está relacionado con los cambios en las contribuciones y con la calidad de la producción como factor diferenciador. ${ }^{19}$ Los datos dan cuenta de niveles diferenciales de instrucción entre migrantes tucumanos y santiagueños. ${ }^{20}$

En sus áreas de origen, estos migrantes realizan tareas diversas principalmente en el sector agrario, como asalariados rurales en la cosecha de limón y en

\footnotetext{
${ }^{19}$ La mano de obra tucumana que arribaba a principios de los noventa se caracterizaba por poseer su bajo nivel de escolaridad (primaria incompleta o sin instrucción). Mientras que una gran parte de los trabajadores trasandinos registraba niveles más altos -primario completa y secundaria incompleta (Kloster et al, 1992).

${ }^{20}$ Más del 80 por ciento de los tucumanos tienen primaria completa y secundaria incompleta; mientras que un 30 por ciento de los santiagueños poseen solamente primaria incompleta o no tienen instrucción.
} 
la zafra azucarera; en caso de ser propietarios de una parcela, desarrollan actividades varias pero subordinadas al proceso migratorio estacional, asumiendo en muchas ocasiones la mujer y/o los hijos la gestión de la parcela, lo cual puede provocar la disminución de las actividades agrarias e incluso el abandono de las mismas. Presentan inserciones multisectoriales, en galpones de empaque (limón, arándano), en la construcción y en el sector terciario (comercio, empleo doméstico, gastronomía, artesanías). Los cambios más relevantes están vinculados con las actividades agrícolas en lugares de origen, menos vinculantes con caña y más relacionados con nuevos cultivos (cítricos, arándano, frutilla). También se amplían los trabajos concretos no agrarios en el sector servicios En general se trata de trabajos de baja calificación y salarios, sin contrato, inestables; predominan las changas lo que genera incluso una frecuente movilidad regional. Las mujeres se ocupan predominantemente en servicio doméstico o en hotelería (mucama, cocinera).

En algunos casos, la inserción laboral a lo largo del año implica la realización de movimientos internos, cortos, dentro de la región de origen; por ejemplo entre trabajadores del área de Río Hondo (Santiago del Estero) hacia la zona cañera de Tucumán. Un proceso interesante que se visualiza tiene que ver con la migración por sustitución dejando nichos de trabajo más descalificados y precarios a otros migrantes, por ejemplo, la sustitución de tucumanos por santiagueños en la cosecha de caña de azúcar. Esta situación es posible porque los primeros se van incorporando a los nuevos mercados de trabajo agrícola (espacios laborales percibidos como más limpios, trabajo menos bruto, con menores exigencias físicas o mejor retribuidas).

Estos movimientos regionales se combinan con desplazamientos extrarregionales, en ocasiones, configurando circuitos que articulan varios espacios productivos. En este sentido, además de la migración hacia el norte de la Patagonia, se identifican otros desplazamiento: hacia la provincia de Buenos Aires para trabajar en áreas turísticas como Mar del Plata o en actividades rurales como la cosecha del durazno en San Pedro o de la papa en la zona de Bahía Blanca; hacia la provincia de Santa Fe para la desfloración del maíz; hacia la provincia de Mendoza para la cosecha de la uva, entre otros. La inserción en diferentes espacios y actividades permite identificar a estos trabajadores como de aquí y de allá/s, y a los desplazamientos como multiformes (Lara 2006a).

\section{Significado social del desplazamiento esta- cional para el migrante}

Otro resultado de la investigación se refiere al por qué y para qué del movimiento. La conducta migratoria contiene sentidos múltiples para los migrantes en las áreas de destino y para la familia en las áreas de origen; para el que se va y para el que se queda.

El desplazamiento estacional implica la ausencia temporal de su lugar vivencial, de pertenencia geográfica y social; de su área de residencia habitual; de su familia y amigos. Todos los años se ven sometidos a un alto grado de incertidumbre como consecuencia tanto del alejamiento de sus vínculos afectivos y pautas culturales, como del establecimiento de nuevas relaciones sociolaborales. En este sentido, la migración puede ampliar los horizontes socioculturales, "Abrir aquellos elementos de las relaciones laborales o de la convivencia familiar del encierro local, jerarquizado y patriarcal que suele mantenerlos indiferenciados, naturalizados" (Giarracca et al, 2001: 309). Este desplazamiento temporario se caracteriza por una reversibilidad renovada, en tanto registra una repetitividad cíclica del trayecto efectuado en destinos bien definidos: el área de residencia habitual/legal y el/las área/s de residencia/s transitoria/s. Por esta razón, se puede hablar de la configuración de un "trabajador migrante estacional permanente".

A nivel de representación, la movilidad resulta la alternativa digna de estar incluidos transitoriamente como asalariados. La noción experiencia próxima nos permite ver la forma cómo la precariedad del trabajo y la vulnerabilidad de las condiciones de vida de los trabajadores logran el efecto de minimizar los riegos cotidianos que ellos enfrentan. Porque justamente es la flexibilidad convertida en precariedad la que hace ver en un trabajo mal pagado, sin seguridad social, intermitente, la ventaja de no estar desempleado (Lara, 2006b) o tener trabajo en palabras de los propios trabajadores golondrinas. El valor asignado al trabajo/empleo es el sentido más profundo asignado por los migrantes norteños a su conducta y se inscribe en el marco interpretativo que Seefoó (2005) señala para los jornaleros de Zamora 
en México. En ambos casos, lo que más le teme el peón de campo o trabajador rural no es a las malas condiciones o los potenciales peligros del trabajo sino a la desocupación. Sin embargo, la necesidad de maximizar los ingresos para llevar la mayor cantidad de dinero a sus áreas de origen, los transforma en una mano de obra sujeta a un consumo escaso de bienes y servicios.

En el lugar de destino, suelen encontrarse aislados social y geográficamente debido a residencia transitoria y dispersa en las explotaciones agrícolas. Esta situación ha conducido históricamente a la invisibilidad social, sindical y política de los trabajadores golondrinas, posicionándolos en tareas más precarias y vulnerables de la actividad. En la actualidad aparecen signos de mayor clarificación del fenómeno y algunos intentos, aunque débiles, de acciones protectorias y políticas preventivas (registro de trabajadores, libreta de empleo, subsidio al desempleo limitado por estacionalidad, aumento del trabajo en blanco), pero que no llegan a revertir aún su posicionamiento frágil y subalterno en la estructura social.

\section{Significado social para la familia en lugar de origen}

Como mencionamos, la ausencia de oportunidades laborales estables y permanentes en algunas provincias del NOA, principalmente en los meses de verano, ha provocado históricamente prácticas alternativas de obtención de ingresos que incluyen la migración estacional hacia otras regiones como estrategia de reproducción social. Para algunas familias, esta necesidad de salir en búsqueda de un trabajo transitorio, forma parte de sus trayectorias vitales y se va transmitiendo de padres a hijos; la migración representa una opción natural en sus vidas y en su propia identidad.

En la comunidades de origen de los migrantes, desde enero hasta fines de marzo, se observa una marcada ausencia de hombres jóvenes y jóvenes adultos lo que implica un reacomodamiento de los roles al interior del núcleo familiar con soledades $y$ riesgos.

La decisión de migrar no sólo significa dejar periódicamente la familia y los amigos sino también involucra reposicionamientos en la unidad doméstica y respecto de la división sexual del trabajo. Se trata de un desplazamiento mayoritariamente masculino; la salida de los hombres es una decisión modelada al interior del hogar y sobre la base del proveedor masculino (en este sentido, el hombre se siente en la obligación de salir a buscar un empleo y un salario que le permita realizar esa función). Estas circunstancias determinan un modelo de hogar caracterizado por la ausencia temporaria de varones (el jefe y/o otros integrantes de la familia, por lo general, los hijos mayores). El alejamiento temporal determina la redefinición familiar de funciones y tareas. Se modifican las relaciones sociales del grupo de pertenencia porque la migración estacional altera la organización de la familia y la división del trabajo en el seno de la misma. La mujer debe asumir la jefatura del hogar y en el caso de familias campesinas, la gestión de la parcela: el cuidado de los animales, los cultivos. Por otra parte, desdibuja el vínculo filial, según la percepción del propio trabajador y de los miembros en el hogar. Desde su partida, la comunicación entre migrante y familia dejaba de ser frecuente pero en los últimos años cambió con la telefonía celular.

El trabajo estacional se constituye en un complemento importante del ingreso familiar a través de giros periódicos de dinero y/o en el momento del retorno. Ese ingreso puede tener diversos destinos: mejoramiento de la vivienda, educación de los hijos, adquisición de artefactos para el hogar, ropa y alimentos, de insumos para la parcela (semillas, animales, etc.) e incluso la compra de un coche o de una moto; le permite reproducir o mejorar sus condiciones de vida. Para ello existe una cuidadosa organización del presupuesto familiar tanto en época de movilidad como de permanencia debido a la incertidumbre de inserción laboral en el resto del año. Esta característica es un claro indicador del modo de vida del migrante y su familia, y de reversibilidad renovada del proceso migratorio.

Respecto del carácter reciente o antiguo de los comportamientos en las distintas generaciones los datos nos llevan a plantear la migración estacional como una práctica resignificada en un contexto actual de profundización de controles institucionales de carácter laboral protectorio que impactan en la forma y el nivel de inclusión, en los derechos ciudadanos. 


\section{HALLAZGOS EMPÍRICOS Y REFLEXIÓN ANALÍTICA}

Los resultados entendemos contribuyen a ampliar la visibilización de los comportamientos migratorios estacionales y de la movilidad del capital y del trabajo. Los datos conducen a la ruptura de las imágenes naturalizadas de irrelevancia del fenómeno y de homogeneidad de las situaciones migratorias.

La movilidad estacional, adquiere sentido en los contextos macroeconómicos y regionales, y en las dinámicas microsociales (prácticas y estrategias de los sujetos migrantes). Es decir, es resultado de disposiciones y comportamientos en respuesta a las condiciones estructurales que la modernización genera, así como el acceso diferencial a los recursos, a las opciones laborales y al poder, pobres de influencia, desafiliados, desprotegidos. Los desplazamientos de trabajadores agrícolas comportan, al decir de Bourdieu y Wacquant (1995), acciones objetivamente orientadas y socialmente inteligibles.

Un resultado de la investigación empírica es la constatación de la persistencia y, más aún, del incremento de los trabajadores migrantes estacionales en la actividad frutícola del norte de la Patagonia; otro resultados tienen que ver con los cambios en el perfil, en los contextos y en el propio movimiento. Los sujetos, sus prácticas y el sentido de la conducta migratoria dan cuenta de una dinámica renovada respecto de un fenómeno de vieja data en los estudios rurales. En conjunto, la investigación avanza revirtiendo la opacidad del fenómeno y modificando su imagen generalizada como irrelevante, homogénea, estática, con lógicas consecuencias para la intervención.

\section{A MANERA DE CIERRE}

\section{Trastienda de una línea de investigación}

El trabajo expresa los recorridos teóricos y procedimentales en la construcción social de datos y en su reflexión analítica. Se muestra la trastienda de una investigación y a la vez el devenir de un tema tradicional en un contexto modernizado. El desarrollo empírico se sitúa en una región de producción intensiva bajo riego orientada al mercado mundial, con elevados requerimientos de migrantes estacionales con opacidad en su registro y en la imagen societal.

Desde la ciencia social crítica y mediante la ruptura de lo obvio, presentamos una línea de investigación en donde los datos y hallazgos desnaturalizan representaciones y desmenuzan situaciones analíticamente. El propósito de este trabajo ha sido mostrar las decisiones teórico-metodológicas que subyacen y dar nuevas respuestas de indagación central acerca de la naturaleza de la migración estacional en una cadena frutícola. En ese quehacer redefinimos las categorías interpretativas y avanzamos en el desarrollo empírico.

Las condiciones contextuales sitúan a los migrantes en el modo social relacional donde están presentes relaciones de poder y laborales (Bourdieu, 1999); las que orientan objetivamente los comportamientos migratorios. Mostrar los sujetos sociales y sus periplos de trabajo entendemos profundiza el conocimiento analítico de la migración de trabajadores agrícolas. Se trata de uno de los modos subalterno de inserción al mundo del trabajo, inserción, que continúa siendo precaria en general, aunque con nuevos rasgos por la acción del Estado y de las organizaciones sociales.

En este marco, entendemos que los condicionantes estructurales direccionan, limitan o facilitan los comportamientos migratorios, sobre las cuales los trabajadores golondrinas construyen sus espacios de vida y de trabajo; subyacen y orientan las estrategias mediante las cuales esos trabajadores, desde distintas posiciones sociales intentan, individual o colectivamente, subsistir o mejorar su situación. Por otro lado, hallamos que los mecanismos de inserción laboral del migrante de carácter flotante, seminómade, no constituye un rasgo aislado sino que forman parte de las estrategias familiares de reproducción social (Álvaro, 2008).

\section{Emergencia resignificada de un viejo tema: la migración de trabajadores rurales}

Las migraciones estacionales agrícolas no son un fenómeno nuevo ni entran recientemente en la agenda de las ciencias sociales; En el caso en estudio, acompañan desde los inicios el desarrollo de la actividad productiva. Lo novedoso en el contexto de modernización globalizada es el cambio en el 
volumen y en la direccionalidad del movimiento, la heterogeneidad de los sujetos que migran, los cambios en los perfiles sociodemográficos asociados a los requerimientos de calidad y buenas prácticas que redefinen la contribución de estos trabajadores. Los distintos tipos de control del proceso de trabajo por el gran capital, se encuadran en la inserción laboral flexible aunque con intersticios (intervenciones del Estado, de organizaciones sociales) que estarían provocando mejores negociaciones salariales y ambientes de trabajo. Estos espacios se generan en un nuevo contexto de creciente visibilización social, sindical y jurídica protectoria.

Si bien hay cambios en las características y en los tipos de migrantes que prevalecen, hay continuidades en la lógica, es decir, en el "por que" de la conducta migratoria, en el sentido de experiencia próxima; y en el significado social, es decir, el "para qué" que tiene el desplazamiento para el trabajador que lo asume y para su familia. Persisten condiciones adversas, inciertas, períodos de des/subocupación en áreas de origen por abandono de actividades o extensión de la mecanización, ambientes y condiciones laborales desfavorables, crisis del empleo urbano. Perduran necesidades básicas insatisfechas en los hogares y la migración continúa siendo una estrategia familiar para la reproducción social. En torno a las persistencias y cambios acordamos con Barel en (Hintze, 1987:13) que “....es necesario romper la concepción de que la reproducción se asocia con la ausencia de cambio. Parece más correcto suponer de acuerdo con este autor que la perpetuación de ciertos sistemas sociales en el tiempo y en el espacio; y su cambio son constitutivos de la reproducción social. Esta última es una forma particular de combinación de invariancia y cambio, en la cual la invariancia es necesaria al cambio y viceversa. La predominancia de uno de estos aspectos sobre el otro caracteriza a un sistema social en el lapso de tiempo".

Las reflexiones analíticas se enmarcan en la premisa inicial de cuestionamiento a imágenes naturalizadas acerca de la migración estacional y se muestra la relevancia de este proceso y la heterogeneidad de situaciones y de sujetos. La tensión entre cambios y continuidades se expresa en el perfil del trabajador temporario, en el significado de la propia movilidad espacial, conformando una práctica migratoria donde se combinan rasgos modernos y más tradicionales. Los desplazamientos de trabajadores agrícolas, su persistencia y su diversidad forman parte del contexto actual de modernización y de los propios senderos de acumulación del capital en regiones de exportación (Bendini, 2006). Es decir, el desarrollo presentado nos conduce a la resignificación del tema. Como en otras regiones de América Latina, lo viejo se esconde tras lo moderno y forma parte de la paradoja modernización/exclusión. En ese escenario, las condiciones de una agricultura moderna global se plasman en mundos del trabajo con la mediación de herencias históricas que aún persisten en nuestra sociedad. Es decir, que lo moderno se constituye por dentro de los viejos rasgos, recreando formas que parecerían incompatibles pero que en realidad se integran a los senderos de acumulación del gran capital (Tsakoumagkos y Bendini, 2000). Como expresa José de Souza Martins en Setúbal (2007) el pasado se esconde, y a veces se esconde mal, por detrás de la apariencia de lo moderno.

\section{Nuevos interrogantes}

A partir de las múltiples correspondencias entre la investigación empírica y la reflexión interpretativa, constatamos que la teoría acompaña todo el proceso de producción de conocimiento y provoca la generación de nuevos interrogantes y campos a indagar (Sautu, 2003). En el comportamiento migratorio intervienen no sólo aspectos de la oferta y la demanda laboral sino también el hecho que las relaciones entre trabajadores agrícolas y empresas/productores se establecen dentro de un contexto social más amplio atravesado por procesos económico-tecnológicos, de políticas públicas, mundos étnicos y culturales, y redes sociales (C. de Grammont y Lara Flores, 2000, Tsakoumagkos, 2004). Sin duda obran condicionamientos estructurales pero intervienen también micro dinámicas familiares, comunitarias, trayectorias vitales y generacionales que especifican las conductas y sus sentidos dando lugar a una diversidad de situaciones y heterogeneidad de sujetos que cuestiona la visión simplista y homogénea de la migración y de los migrantes.

Intentamos comprender genéricamente el fenómeno acá contextuado de la movilidad de trabajadores agrícolas, a través del desarrollo de la práctica migratoria a una región agrícola de exportación. Este avance nos convoca, a su vez, a profundizar el carácter y su función articulando procesos laborales 
y migratorios con las "primeras inscripciones sociales" (Giarracca et al, 2000:121); es decir, nos lleva a ahondar en las carreras vitales y trayectorias familiares generacionales como parte de la historia misma del capitalismo agrario en regiones no pampeanas de Argentina. Finalmente y como desafío es posible también redirigir la mirada analítica e introducirnos en ámbitos propositivos. Tanto a nivel de reflexividad social como de diseño de políticas, el estudio de la migración temporaria deja de ser un fenómeno aislado y se integra a contextos explicativos de la dinámica social; en otras palabras, se ubica en terrenos analíticos de amplio interés en los estudios agrarios tales como la integración social y el desarrollo rural.

\section{BIBLIOGRAFÍA}

Alfaro, M. I. y Berenguer, P. (2003): “Las pequeñas y medianas empresas en el complejo citrícola”. En Terceras Jornadas Interdisciplinarias de Estudios Agrarios y Agroindustriales. Buenos Aires: UBA. En formato electrónico.

Alvaro, M. B. (2008): Informe pre-final de Tesis Doctoral en Ciencias Sociales y Humanas, Universidad Nacional de Luján. Edición digitalizada.

Barreiro, T. (1975): "La quiebra de la ciencia social acrítica”. En Revista Paraguaya de Sociología. Año 12 - № 32, Enero - Abril.

BENENCIA, R. (2001): "Introducción. Los estudios sobre migraciones internas: la actualización de un fenómeno que persiste". Estudios Migratorios Latinoamericanos, No 47, Año 16. CEMLA. Buenos Aires.

BenENCIA, R. y QuARanta, G. (2003): "Producción y trabajo en frescos de exportación en Argentina”. En M. Bendini y N. Steimbreger Territorios y organización social de la agricultura. Cuaderno GESA 4. La Colmena. Buenos Aires.

BENDINI, M. (2006): "Modernización y persistencias en el campo latinoamericano". Revista ALASRU. Nueva Época .No 4, noviembre. Chapingo. México.

BendinI, M. (2007): "Prólogo". En M. Radonich y N. Steimbreger (coordinadoras), Reestructuraciones sociales en cadenas agroalimentarias. Cuaderno GESA 6. La Colmena. Buenos Aires.

Bendini, M.; Pescio, C.; Radonich, M.; Steimbreger, N.; Tsakoumagkos, P. et al; (1999), La división social, sexual y espacial del trabajo frutícola en la cuenca del río Negro. Transformaciones agroindustriales y demanda laboral. Informe final D037. UNCo. Neuquén. Argentina. Edición digitlizada.

Bendini, M. y LaRa Flores, S. (2007): "Espacios de producción y de trabajo en México y Argentina. Un estudio comparado en regiones frutihortícolas de exportación". Revista Interdisciplinaria de Estudios Agrarios. Número 26/27. Pp. 13-62. CIEA FCE UBA. Buenos Aires.

Bendini, M. y Steimbreger, N. (2008): Les travailleurs saisonniers dans les espaces de production du Nord de la Patagonie. Des migrations frontalières aux mouvements internes de population. En Migrations Societé, CIEMI, vol. 20, 115 Janvier fevrier.

Bolsi, A. Madariaga, H. y Paolasso, P. (2008): "La calidad de vida de la población del Noreste Argentino". En Velazquez, Guillermo. GEOGRAFÍA y BIENESTAR. Situación local, regional y global de la Argentina luego del censo de 2001. EUDEBA. Buenos Aires.

Bonaudo, M. (2007): "Historia o historias rurales: un campo de diálogo entre historiadores". En O. Graciano, y S. Lázzaro (comp) La Argentina Rural del Siglo XX. Fuentes, problemas y métodos. Editorial La Colmena. Buenos Aires.

Bourdieu, P. (1999): "El espacio para los puntos de vista", Revista Proposiciones, núm. 29: Historias y relatos de vida. Investigación y práctica en las ciencias sociales, Santiago de Chile, Ediciones Sur.

Bourdieu, P. y Wacquant, L. (1995): "Respuestas por una Antropología Reflexiva". Editorial Grijalbo. México.

Canabal C. B. y Flores F.J. (2001): “Organización popular en la montaña de Guerrero" en B. Canabal (coord.) Los caminos de la montaña de Guerrero. CIESAS:UAM-Xochimilco, México.

C. de Grammont, H. y Lara Flores, S. (2000): Nuevos enfoques para el estudio del trabajo rural en México. En Cuadernos Agrarios, Nueva Época, número 19-20. México.

CENEP. (1995): Boletín del Sidema. Vol. 5. N 12. Argentina.

CHоnchol, J. (1996): Sistemas Agrarios en América Latina. De la etapa prehispánica a la modernización conservadora. Fondo de Cultura Económica. Chile. 
Domenach, H. y Picouet, M. (1995): Las Migraciones. Dirección General de Publicaciones. UNCórdoba. Argentina.

Setúbal, M. (2007): "Refuncionalizacao de servidao. Un análise da permanencia da fomas de escravidao na agroindustria canvieira de Campos Dos Goytacazes" en J. Novaes y F. Alves Migrantes. Trabalho e trabalhadoes no Complexo Agroindustrial Canavieir. EdUFSCar. San Carlos, Brasil.

DowBor L. (2001): A reprodução social. Tecnologia, globalizção e gobernabilidade. Editora Brasiliense.

Forni, F.; Benencia, R. y NeImAn, G. (1991): Empleo, estrategias de vida y reproducción. Hogares rurales en Santiago del Estero. CEIL - Centro Editor de América Latina. Buenos Aires.

Gallart, M. A. (1992): “La integración de métodos y la metodología cualitativa”. En Forni, F. et al Métodos cualitativos II. Centro Editor de América Latina. Buenos Aires.

García BARLet, M.(2002): Mercado laboral www.lanacion.com.ar.

Giarraca, Norma; Bidaseca, Karina y Mariotti, Daniela. 2000. Tucumanos y Tucumanas. Zafra, trabajo, migraciones e identidad. Editorial La Colmena. Buenos Aires.

Giarracca, N.; BidasecA, K. y Mariotti, D. (2001): “Trabajo, migraciones e identidades en tránsito: los zafreros en la actividad cañera tucumana”. En N. Giarracca (comp.), ¿Una nueva ruralidad en América Latina? CLACSO. Buenos Aires.

Galtung, J. (1966): Teorías y métodos de la investigación social. EUDEBA. Tomo I. Bs. As.

García Borrego, I. "Las estrategias familiares de reproducción de marroquíes y ecuatorianos en Murcia". Ponencia presentada en Seminario CEMLA, CEIL-UBA, Buenos Aires.

Hintze, Susana. (1987): "La reproducción de los sectores populares: Estrategias y reivindicaciones". Departamento de Ciencias Antropológicas. Buenos Aires. Edición digitalizada.

Kloster, E.; Radonich, M.; Steimbreger, N. et al. (1998): "Redistribución y movilidad territorial de la población en el oeste neuquino". Informe Final Proyecto de Investigación. . Dpto. de Geografía, Universidad Nacional del Comahue.

Kloster, E.; Radonich, M.; Steimbreger, N.; Roglich, E. y Vecchia, T. (1992): “Migraciones estacionales en el Alto Valle de Río Negro y Neuquén en el último decenio". Informe Final Proyecto de Investigación. Dpto. de Geografía, Universidad Nacional del Comahue.

LARA Flores, S. $\left(2006^{\mathrm{a}}\right)$ : "Mercado de trabajo rural, nuevos territorios migratorios y organizaciones de migrantes" V Congreso de la Asociación Nacional de Estudios del Trabajo. Oaxtepec. México. Mimeo.

LARA FloRes, S. (2006 b): Reseña Bibliográfica del libro de José Luis Seefoó, "La calidad es nuestra, la intoxicación...jde usted!". Revista Interdisciplinaria de Estudios Agrarios, N2 25. 2do. Semestre. Buenos Aires.

LARA FloRES, S. (2009): "Los 'encadenamientos migratorios' en regiones de agricultura intensiva de exportación en México". En Jornadas Internacionales de Investigación Migraciones, trabajo y cadenas globales agrícolas. Murcia. España. Edición digitalizada.

Lara Flores, S. y C. de Grammont, H. (2003): "Los efectos de las migraciones rurales internas en la conformación de los grupos domésticos en México". En Bendini, M.; Cavalcanti, S.; Murmis, M. y Tsakoumagkos, P. (comp.) El campo en la sociología actual. Una perspectiva latinoamericana. Editorial La Colmena. Buenos Aires.

Mora y Araujo, M. (1980): "Evidencia e Inferencia en la Investigación Social". Primer Simposio Interdisciplinario sobre Metodología de la Investigación en Ciencias Humanas. UNSalta. Argentina. Mimeo.

Murmis, M. (1991): Tipología de pequeños productores campesinos en América. En Ruralia: Revista de Estudios Agrarios. FLACSO. Buenos Aires.

Murmis, M. y Bendini, M. (2003): "Imágenes del campo latinoamericano en el contexto de la mundialización”. En Bendini, M.; Cavalcanti, S.; Murmis, M. y Tsakoumagkos, P. (comp.) El campo en la sociología actual. Una perspectiva latinoamericana. Editorial La Colmena. Buenos Aires.

Pedreño CÁnovas, A. (1999): Del jornalero agrícola al obrero de las factorías vegetales. Ministerio de agricultura pesca y alimentación, Secretaría General Técnica. Madrid.

Pachano, S. 1986. "Se fue a volver". En PISPAL-CENEP Se fue a volver. Seminario sobre migraciones en América Latina. El Colegio de México. México.

Palau, T y Heinkel, M. (1982): "Desplazamientos espaciales temporales de la fuerza de trabajo en las fronteras agrícolas. El caso del Alto Paraná. Paraguay”. En S. Pachano, Se fue a volver, ob.cit.

RADOnich, M. y Steimbreger, N. (1996): "Redes sociales, migración contemporánea y movilidad estacional en el Alto Valle de Río Negro y Neuquén". Edición digitalizada.

Riffo, M.; Bendini, M.; Colantuono, M.; Bonifacio, J.; Arratia, M. et al (1997), Efectos socioambientales de la modernización frutícola en Chile y Argentina- Proyecto binacional IPGH-OEA, Dpto. de Geografía (Universidad de Chile) - GESA y Dpto. de Geografía (Universidad Nacional del Comahue). 
Rodríguez, D y Venegas. (1986): “Migración temporal y economía campesina. Nuevos problemas para viejas teorías". En C. Reboratti, C. (compilador). Se fue a volver... Seminario sobre migraciones temporales en América Latina. México: PISPAL, CIUDAD, CENEP.

Reboratti, C. (1983): Peón golondrina: cosecha y migraciones en la argentina. Centro de Estudios de Población. CENEP, No 24. Buenos Aires.

Sabalain, C. y Reboratti, C. (1982): "Vendimia, zafra y alzada. Migraciones estacionales en la Argentina", En A. Lattes (comp.) Migración y desarrollo (Buenos Aires: CLACSO) Serie Población 6.

SAUTU, R. (2003): Todo es teoría. Objetivos y métodos de investigación. Ediciones Lumiere. Buenos Aires.

Secretaría de Fruticultura (2005): Censo de áreas irrigadas en la provincia de Río Negro (CAR) Ministerio de Producción de Río Negro. Argentina.

SEEFó, J. (2005): La calidad es nuestra, la intoxicación...jide usted! Colegio de Michoacán.

StAKE, R. (2005): Investigación con estudio de casos. Ediciones Morata. Madrid, España.

TAdeo, N. y Palacios, P. (2004): "El empleo agrícola en el contexto de reestructuración económica argentina: los cosecheros del citrus en el noreste entrerriano". En Estudios del Trabajo, 27. ASET. Buenos Aires.

THEBorn, G. (2006): "O desafio mundial ás ciencias sociais. Abordagens para análise global". En.Barrerira, Rego y Dwyer (org.) Sociologia e conhecimento além das fronteiras. Editorial Tomo. Porto Alegre.

TORRADO, S. (1980): Estrategias de supervivencia y de reproducción social. CLACSO PISPAL, Buenos Aires.

Tsakoumagkos, P. (2004): "Prólogo". En M. Bendini y C. Alemany. Crianceros y Chacareros en la Patagonia. Cuaderno GESA 5. Editorial La Colmena. Buenos Aires.

Tsakoumagkos, P. y Bendini, M. (2000): "Modernización agroindustrial y mercado de trabajo ¿flexibilización o precarización?. El caso de la fruticultura en la cuenca del río Negro" en Revista Latinoamericana de Estudios del Trabajo. Año 6. $\mathrm{N}^{\circ} 12$.

VASILACHIS, I. (1993): Métodos cualitativos I - Los problemas teóricos epistemológicos. Centro Editor de América Latina. Buenos Aires.

Vapnarsky, C. y Pantelides, E. (1987): La formación de un área metropolitana en la Patagonia. Población y asentamiento en el Alto Valle. CEUR. Buenos Aires.

VeLÁzquEZ, G y Vega A. (2008): "Relación entre calidad de vida y categorías urbanas según regiones". En G. Velazquez, Geografia y bienestar. Situación local, regional y global de la Argentina luego del censo de 2001. EUDEBA. Buenos Aires.

Wainerman, C. y Sautu R. (1997): La trastienda de la investigación. Universidad de Belgrano, Buenos Aires. 